\title{
THE POLITICAL ACTOR'S BRAND IN THE 2012 BACĂU ELECTORAL CAMPAIGN
}

\author{
Cristina Cîrtiță-Buzoianu \\ "Vasile Alecsandri” University of Bacău \\ cristina_buzoianu@yahoo.com
}

\begin{abstract}
This paper aims to analyze the image and identity of political actors during an electoral campaign, as these two elements are defining for political marketing in attracting and convincing voters. With that in mind we will monitor the image of the two candidates for the position of mayor in the 2012 electoral campaign in Bacău, as it appeared in the written local press. The analysis of the two politicians will be made from the perspective of two preestablished image indicators: the political and the human dimensions. Each of the two dimensions has sub indicators pre-established in order to validate the general mediatized image of the candidate. Regarding the political dimension we will measure the sub indicators: political communication, attitude towards corruption, interest for civil problems, the ability to negotiate and political project, while the human dimension has the following sub indicators: faith, empathy, morality, honesty, charisma, consistency and leadership. Thus, we will try to identify if there are major differences between the two dimensions, for the two candidates, from a quantitative as well as a qualitative perspective.
\end{abstract}

\section{Keywords}

political marketing; communication; brand; image; press.

\section{JEL Classification}

M31, M37

\section{Introduction}

Departing from Lance Bennett's belief in "lifestyle politics as identity politics" (Bennett , 1998), we consider that the political identity exhibited by a candidate and the social image must be constructed so as that no major discrepancies are registered. Today's electorate is increasingly preoccupied with the lifestyle of political figures, meaning to the expression of an identity that is affirmed within a society characterized through socio-cultural communities that the political system cannot ignore. Identity is manifested in symbolic productions: the style of speeches, the rhythm of activities, habits. From the perspective of the evolution of identity, we can observe a slow rhythm, since it is mentally perceived as a trajectory. As a project still under construction, identity needs to be backed by legitimacy, charisma and authority which in turn contribute to the image consolidation of the political actor. In the electoral campaigns of contemporary society informal legitimacy has become stronger than elective legitimacy, which is the main form of representation in a democracy. The diversity of contemporary lifestyles has imposed the political realignment and the extension of multiculturalism, and the diversity of belonging groups makes formulating representative policies even more difficult. Therefore political figures have had to look for new criteria for garnering political legitimacy, to surpass the standards policies were based on, performance, sobriety or notoriety and highlighting their political personality. The political image has replaced ideology, and the discursive strategies outweigh political actions. Politicians attempt to become 
renowned and use differentiation, association, public participation and repetition in order to send messages. "The political image brand is represented by the totality of signs and personality characteristics that the mass-media induces into political audience, relative to a person that develops constant political activity" (Săftoiu, 2003). In fact the political image brand is a relatively simplistic synthesis, a caricature, a figure composed of two or three main characteristics positioning the political personality in the mind of the electorate, once and forever. Once this image brand is formed in the consciousness of the political audience politicians will very difficultly make any changes to the perception of the electorate. Political journalists aid the phenomena named the hardening of the image brand of politicians.

\section{Case study}

Our case study aims at monitoring the political brand within the 2012 local political campaign in Bacău. In that sense, we have analyzed two local newspapers, Deşteptarea and Ziarul de Bacău, the best rated from the point of view of circulation numbers, in order to establish the visibility of the two candidates to the Mayor's Office for the city of Bacău: Romeo Stavarache, PNL and Dumitru Sechelariu, independent candidate. Both had already occupied this position and had experience in local administration. The local electoral campaign was aggressive and involved high investment costs in marketing strategies and techniques, with harsh speeches addressed at the opposing candidate, not lacking in personal attacks and colorful language. The two candidates both had support from the media trusts, with the support of Ziarul de Bacău and 1 TV Bacău for Romeo Stavarache being particularly well known as well as the other side of Dumitru Sechelariu having the support of the trust Deşteptarea which included $T V$ Bacău. By monitoring the two newspapers we intended to verify that the visibility of candidates within the two newspapers was sustained by the positive /negative attitude towards the two candidates. In order to validate these objectives we established two dimensions, one political and one human, in order to correlate political activities, as they were transposed in the local press, with the human profile of the candidate and the way it was perceived by the electorate. Within each indicator we established a series of sub-indicators in order to establish the image levels in order to correlate them with media visibility. The political dimension had the following sub-indicators: political communication, attitude towards corruption, interest for civil problems, the ability to negotiate and political projects. The human dimension had the following sub indicators: faith, empathy, morality, honesty, charisma, consistency and leadership. The qualitative analysis was done through source tendency analysis (Chelcea, 2001) relative to the analyzed social actor. The analysis of the frequency we can highlight the attitude of the source (expressed through message), which can be positive, negative, or neutral.

In order to analyze the tendency we will use the formula: $A T=(F-D) / T$, where:

$$
\begin{aligned}
& \text { AT=the tendency analysis index; } \\
& \mathrm{F}=\text { number of favorable units; } \\
& \mathrm{D}=\text { number of unfavorable units; } \\
& \mathrm{T}=\text { the total number of units. }
\end{aligned}
$$

By coalescing the two newspapers there was a total of 384 articles in the two newspapers, that is 200 in Deşteptarea and 184 in Ziarul de Bacău. Also, the distribution of each candidate within the two newspapers, relative to the established dimensions, was unequal. In Deşteptarea, Romeo Stavarache had 84 articles, while 
Dumitru Sechelariu had 136 articles. Conversely, in Ziarul de Bacău, Romeo Stavarache had 111 articles, while Dumitru Sechelariu had 73 articles.

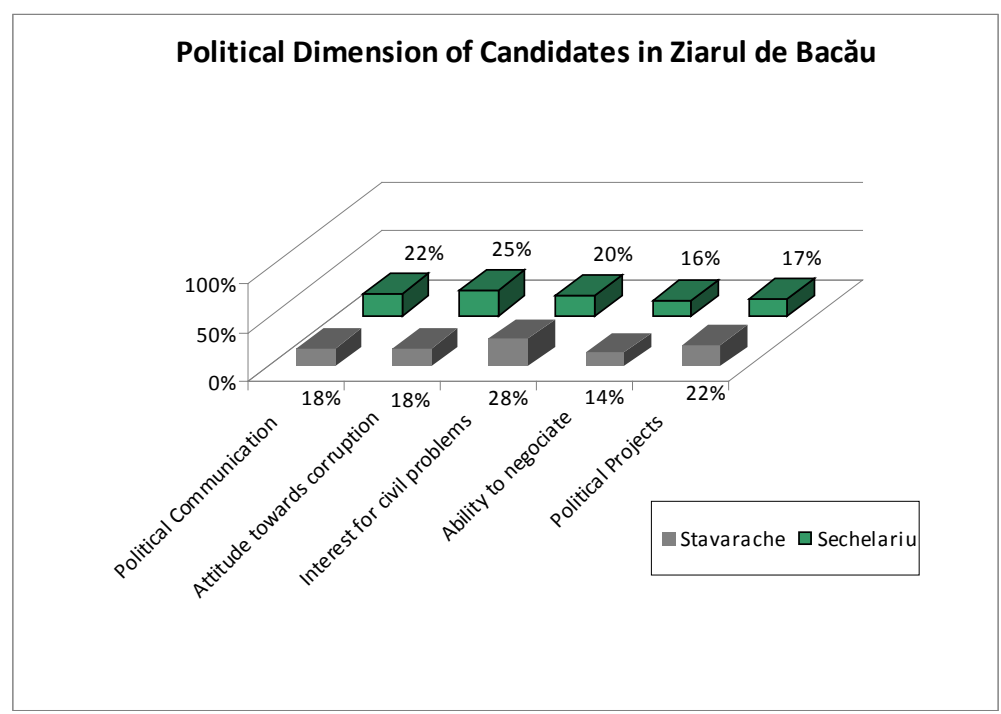

Figure 1 Political Dimension of Candidates in Ziarul de Bacau

The political dimension of Romeo Stavarache gathered a number of 50 articles in Ziarul de Bacău. At the level of sub-indicators, which we established through monitoring in order to make note of the increased attention paid to projects and the way in which the mayor implemented policies within the local communities. The political dimension of Dumitru Sechelariu gathered 34 articles in Ziarul de Bacău.

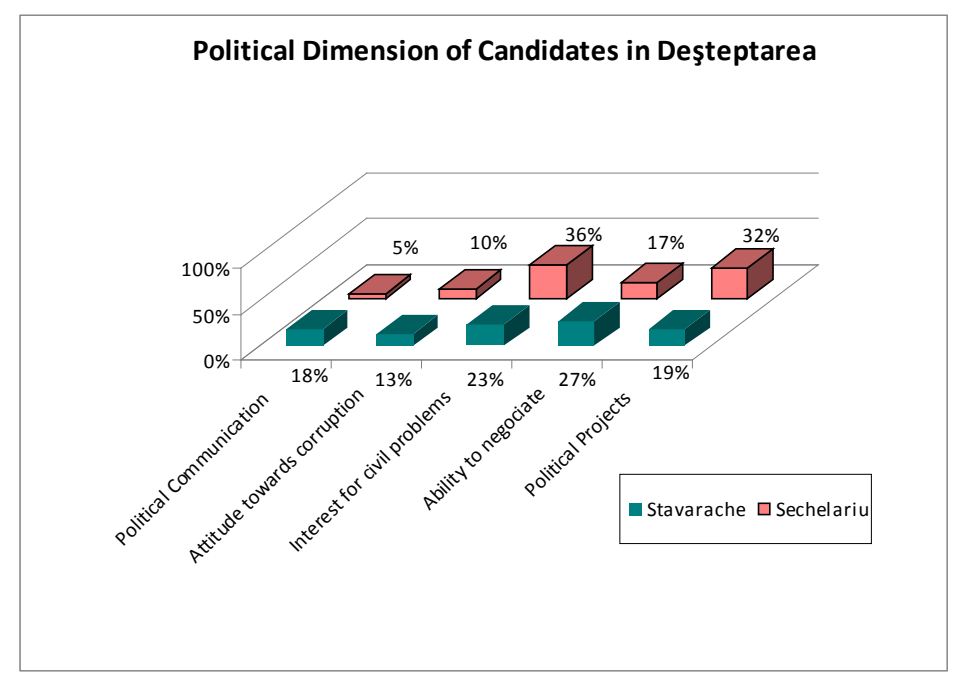

Figure 2 Political Dimension of Candidates in Deșteptarea 
The political dimension of Romeo Stavarachein Deşteptarea reached a number of 32 articles, while Dumitru Sechelariu had 68. From a quantitative perspective, the preestablished political dimension sub-indicators in Ziarul de Bacău reached fairly balanced percentages, without major discrepancies in terms of categories or candidates. The articles referring to the PNL candidate mostly addressed the interest in civil problems with $28 \%$ and political projects at $22 \%$, while the other categories reached close percentages with a favorable tendency. From the perspective of a candidate in office this is justifiable, even more so since his electoral campaign highlighted what the administration achieved during his mandate. Among the positive aspects we mention: The Bacău mayoral office got 40 play areas for the city's children, The mayoral office signed the financing contract for the most beloved place of the locals, the underground passage of Oituz-Sttefan Guse was inaugurated. In Deşteptarea the sub-indicator of the ability to negotiate is maintained at $27 \%$ as well as the interest in civil problems at $23 \%$, but the tendency index is generally negative. As a newspaper backed by his counter candidate the main themes broached were those addressing projects of the previous administration aimed at minimizing and attacking political achievements.

Dumitru Sechelariu reached high percentages in Ziarul de Bacău on the subindicators: attitude towards corruption 25\%, political communication $22 \%$ and interest for civil problems $20 \%$, though the tendency was generally negative, so the high visibility did not make for a plus in image, but rather the opposite. Themes from his previous administration were brought to the fore, and this will also be reflected in the human dimension sub-indicators with 3\% for interest in civil matters and $7 \%$ for honesty. In Deşteptarea the highest percentages were registered by the sub-indicators of interest for civil problems at $36 \%$ and political projects at $32 \%$ as a counter offer to the counter candidate, with a positive preponderance. From a qualitative point of view, Romeo Stavarache had an index of 0.30 while Dumitru Sechelariu had 0,35, with relatively small differences and attacks being present in both newspapers, showing that each candidate tried to promote an electoral offer as well as to attack the image of the other.

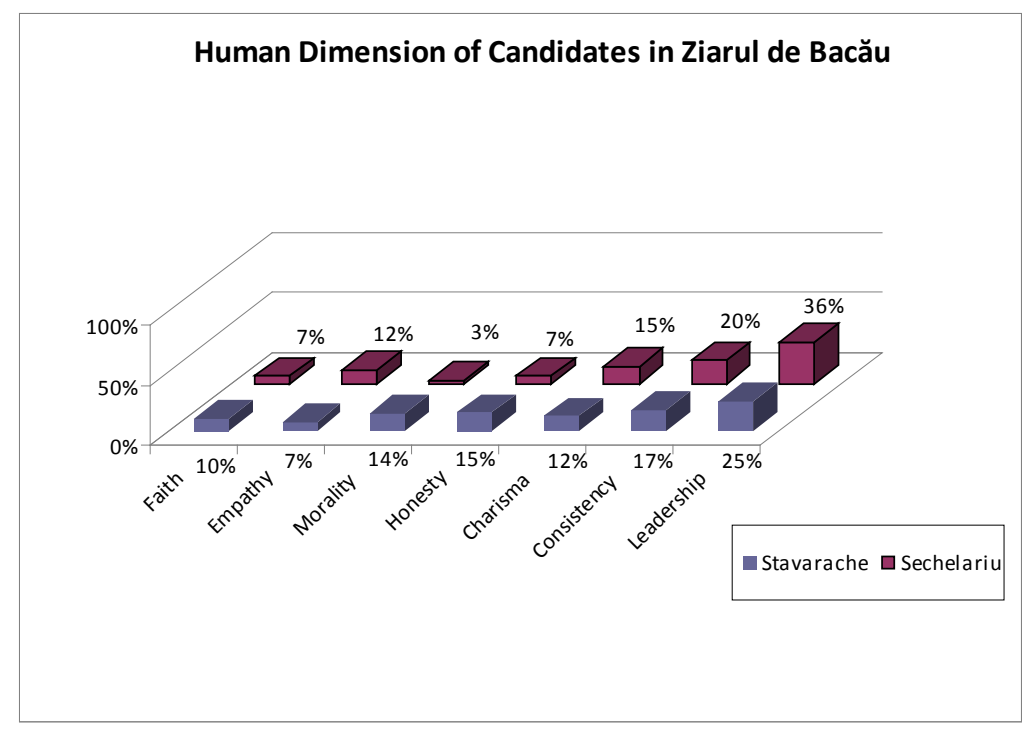

Figure 3 Human Dimension of Candidates in Ziarul de Bacau 
The human dimension of Dumitru Sechelariu in Ziarul de Bacău presented high percentages of leadership and consistency (36\% and 20\%, but with a negative tendency) and lower for indicators such as morality, honesty and faith. In Deşteptarea the human dimension was found in 68 articles. We should note that the same qualities of leadership, charisma and consistency were highlighted with a positive spin in the attempt to improve the candidate's image. Morality and honesty, contested subindicators, at the level of the image, have the same percentage of only $11 \%$. These percentages confirm that Sechelariu is known by the electorate, but has image problems regarding his credibility for the voters.

The human dimension of Romeo Stavarache garnered 61 articles in Ziarul de Bacău and 52 in Deşteptarea. The campaign slogan of Bacău. Home! emphasized idea that Bacău was well administered by its leader, the closeness to the electorate and the stereotype of the hard-working leader. The slogan was satirized in by Deşteptarea: Romica from Focşani despairing because the locals will fire him on June $10^{\text {th }}$. We must underline that throughout the Stavarache administration, Deşteptarea had contested each and every action and political project, which led to a slow erosion of the newspapers credibility amongst the citizens. According to the expert literature, when constantly opposing the actions of a candidate the only result in the end will be the public's saturation, and the effect will be reversed: the denials will cause positive reactions.

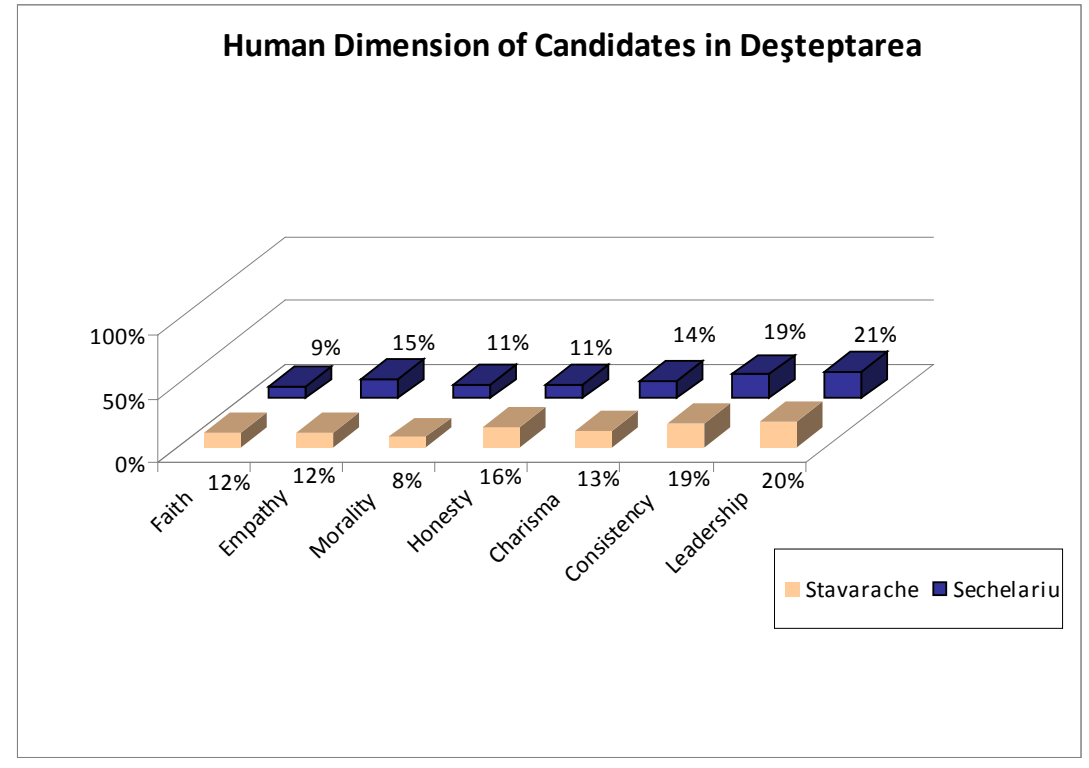

Figure 4 Human Dimension of Candidates in Desteptarea

The human dimension of the candidate Dumitru Sechelariu was based on the campaign slogan: A local like you or Together we'll bring Bacău back to life! through which he was trying to find a communication channel with citizens as well as identify with the problems with which they were faced. This was also apparent from the high percentage of the sub indicator empathy of $15 \%$ in Deşteptarea. It is interesting that we can find common campaign ideas of the two candidates, common projects, the idea of the hard working leader mixed with a good administrator and this city being seen as a home, so the segment of the public is not essentially different. Therefore the 
differences would be determined by the human component, associate with the traits determining the credibility of the candidate in front of the public.

From a qualitative point of view there are differences between the two candidates if we analyze the results comparatively for the two dimensions. Romeo Stavarache has a tendency index of 0.36 for the human dimension, thus surpassing the political dimension index of 0.3 , which means a high percentage of the image chapter and electoral credibility, particularly for a candidate in office who diminishes this indicator throughout the mandate. Dumitru Sechelariu, although he had a higher percentage in the political dimension index, at 0.35 , did not confirm here with only 0.27 for the human dimension. In this case the high notoriety was not backed by credibility and therefore the image brand could no longer be saved.

\section{Conclusions}

The analysis of the two newspapers and of the candidates shows that there was intense media coverage throughout the 2012 local political campaign, though visibility and the positive attitude towards a particular candidate are not always sustained. Nevertheless, the powerful support of the newspapers for each politician in part contributed to the communication with the electorate, so that each candidate could send the desired messages to the public. Political campaigns in recent years have demonstrated that elections are not based on rational voting (the best candidate or political program) but rather on the emotional vote that can often surprise even politicians. Therefore political marketing strategies can contribute to saving a politician who is in difficulty or can demolish a good image won in time. That is the reason why the mass-media plays an essential role in electoral campaigns as an intermediary between the politicians and the voters. The journalists are transformed into the spokesmen of politicians, succeeding in some situations to persuade the electorate. Essentially, political campaigns are not based on politics, but instead on political image. Faces with voters mainly concerned with an emotional vote, Romanian politicians concentrate their effort on persuasive methods, on constructing an image and political brand, good communication with the mass-media and fewer political programs and projects. Therefore the politics of recent years and particularly recent electoral campaigns seemed to the public to be complete theatre scenes, in which the candidates seem successful actors in the attempt to attract voters. It is now essentially not to be effective, but instead to not make major mistakes during the campaign and to maintain the image level you have gained in the common mentality.

\section{References}

Bennett, L. (1998), The un-civic culture: communication, Identity and the Rise of Life Style Politics, Political Science \& Politics, XXXI.

Chelcea, S. (2001), Methodology of Sociological Research: Quantitative and Qualitative Methods, Economics Publishing, Bucharest.

Esser, F., Pfetsch, B. - edit. (2004), Comparing Political Communication, Cambridge University Press, Cambridge.

McNair, B. (2003), An Introduction to Political Communication, Polirom Publishing, Iaşi.

Săftoiu, C. (2003), Political Journalism, Trei Publishing, Bucharest.

Teodorescu, B. (2005), The Best of All Possible Worlds, Comunicare.ro Publishing, Bucharest. 